\title{
POTENTIAL EFFECTS OF CLIMATE CHANGE ON ECOLOGICALLY RELEVANT STREAMFLOW REGIMES
}

Short title: Climate Change and Streamflow Regimes

Sulochan Dhungel ${ }^{\mathrm{a}}$, David G. Tarboton ${ }^{\mathrm{a}}$, Jiming Jin ${ }^{\mathrm{b}}$, Charles P. Hawkins ${ }^{\mathrm{c}^{*}}$

${ }^{a}$ Department of Civil and Environmental Engineering, Utah State University, Logan, UT, USA

${ }^{b}$ Department of Watershed Sciences and Department of Plants, Soils, and Climate, Utah State University, Logan, UT, USA

'Department of Watershed Sciences, Western Center for Monitoring and Assessment of Freshwater Ecosystems, and Ecology Center, Utah State University, Logan, UT, USA

*Correspondence to: C.P. Hawkins, Department of Watershed Sciences, Utah State University, Logan, UT, 84322-5210, USA

E-mail: chuck.hawkins@usu.edu

This is the accepted version of the following article

Dhungel, S., D. G. Tarboton, J. Jin and C. P. Hawkins, (2016), "Potential Effects of Climate Change on Ecologically Relevant Streamflow Regimes," River Research and Applications, 32(9): 1827-1840, http://dx.doi.org/10.1002/rra.3029.

which has been published in final form at http://dx.doi.org/10.1002/rra.3029. 


\section{ABSTRACT}

We assessed the climate-driven changes in ecologically relevant flow regimes expected to occur by the year 2100 in streams across the conterminous United States. We used long-term daily flow measurements from 601 gauged streams whose watersheds were in relatively natural condition to characterize spatial variation in 16 flow regime variables selected for their ecological importance. Principal component analysis of these 16 variables produced five uncorrelated factors that described patterns of spatial covariation in flow regimes. These five factors were associated with low flow, magnitude, flashiness, timing, and constancy characteristics of the daily flow regime. We applied hierarchical clustering to the five flow factors to classify the 601 streams into three coarses and eight more finely resolved flow regime classes. We then developed a random forest model that used watershed and climate attributes to predict the probabilities that streams belonged to each of the eight finely resolved flow regime classes. The model had a prediction accuracy (per cent correct classification) of $75 \%$. We used the random forest model with downscaled climate (precipitation and temperature) projections to predict site-specific changes in flow regime classes expected by 2100 . Thirty-three per cent of the 601 sites were predicted to change to a different flow regime class by 2100 . Snow-fed streams in the western USA were predicted to be less likely to change regimes, whereas both small, perennial, rain-fed streams and intermittent streams in the central and eastern USA were predicted to be most likely to change regime.

KEY WORDS: climate change, flow regime, classification, model, random forest 


\section{INTRODUCTION}

Streamflow regimes (i.e. temporal patterns of streamflow) result from the interaction of climate and watershed features, and will therefore likely be sensitive to climate change. Weather (precipitation and temperature) interacts with geology, topography, soil, and vegetation to influence infiltration, evaporation, and runoff generation, which together determine streamflow (Dingman, 2002; Brutsaert, 2005). Climate change is generally expected to affect one or more of these processes (Tucker and Slingerland, 1997; Bachelet et al., 2001; Held and Soden, 2006; Zhou et al., 2014) and hence streamflow regimes (Nijssen et al., 2001; Stewart et al., 2004; Christensen et al., 2004). These climate-induced hydrologic changes may then alter the ecological structure and function of freshwater ecosystems (Melack et al., 1997; Hauer et al., 1997; Mulholland et al., 1997; Meyer et al., 1999; Döll and Zhang, 2010; Arnell and Gosling, 2013; McManamay et al., 2015). For example, Hauer et al. (1997) concluded that predicted decreases in magnitude and earlier onset of snowmelt runoff in the Rocky Mountain region would make streams and rivers unsuitable for salmonids in the region. Similarly, Mulholland et al. (1997) argued that predicted increases in storm intensities, coupled with larger peak flows and lower base flows, would cause loss of stream habitat as a result of intense flushing events and shorter periods of inundation in riparian areas. In addition to such qualitative predictions of changes to stream ecosystems associated with changes in flow regime, a number of studies have used quantitative hydro-ecological models to assess how predicted future climate is likely to alter ecological flow regimes. For example, based on global water model simulations, Döll and Zhang (2010) concluded that ecologically relevant flow characteristics will be more altered by climate change than they have been by withdrawals and dams. Similarly, the simulations conducted by Arnell and Gosling (2013) that coupled an ensemble of climate model projections with a global 
hydrological model predicted that winter runoff will increase, and summer runoff will decrease in response to climate change in northern parts of the USA by 2050.

Although researchers generally accept that climate change will alter both hydrologic and ecosystem processes in streams, we do not yet possess a robust understanding of how the effects of climate change will differ within and across regions (Tague et al., 2008; Chang and Jung, 2010; Jung et al., 2012). A few researchers have examined the projected effects of climate change on streamflows at a regional scale e.g., (Stewart et al., 2004; Christensen et al., 2004; Maurer and Duffy, 2005; Thodsen, 2007; Reidy Liermann et al., 2012), but to our knowledge, no assessment has been conducted of the potential effects of climate change on the flow regimes of streams across the full range of climatic and physiographic conditions that occur within the conterminous United States (CONUS). At such continental scales, some patterns of flow response to climate may occur that are not apparent in regional studies, which typically encompass smaller ranges of climate and hydrophysical conditions.

In this paper, we examine the potential effects of projected climate change on the natural flow regimes of streams within the CONUS. Such an assessment should help reveal where, within the CONUS, streams and rivers may be especially vulnerable to climate-induced shifts in ecologically important aspects of streamflow, and what kinds of stream are most and least vulnerable. Moreover, we expected the study to help identify the specific climatic factors and watershed attributes that influence the sensitivity of flow regimes to climate change.

\section{METHODS}




\section{General approach}

To address our objective, we had to complete three major tasks: (i) obtain or develop a classification of flow regimes that was informed by ecological theory and applicable to the entire CONUS; (ii) model how flow regime classes vary with current climate and watershed features; and (iii) link this model to downscaled climate projections to predict how flow regime classes may change in the CONUS with long-term changes in precipitation and air temperature. We first selected 16 flow variables that collectively described five aspects of the flow regime that ecologists consider to be important to stream ecosystem structure and function: magnitude, frequency, timing, duration, and rate of change (Poff et al., 1997). We then used principal component analysis (PCA) to identify independent axes of variation in these 16 variables across sites. The PC factors were used in a hierarchical classification to identify different types of flow regimes. We then developed empirical models to predict the most probable type of streamflow regime at individual streams from climate and watershed attributes. These space-for-time models allowed us to predict how the flow regimes present at individual streams sites should change with projected changes in precipitation and temperature.

Several researchers have previously classified US streams in terms of their flow regimes (Sanborn and Bledsoe, 2006; Chinnayakanahalli et al., 2011; McManamay et al., 2012; Reidy Liermann et al., 2012; Archfield et al., 2013), and a few have developed classifications that apply to most of the USA (Poff and Ward, 1989; Poff, 1996; Archfield et al., 2013; McManamay et al., 2014). However, previous classifications largely followed Poff in standardizing flow magnitude variables by either catchment area or mean daily flows. We wanted to use a classification of flow regimes that incorporated the absolute magnitude of flow because (i) flow volume is important to stream ecosystem structure and function (Vannote et al., 1980; Freeman 
and Marcinek, 2006; McKay and King, 2006; Anderson et al., 2006; Poff and Zimmerman, 2009; Carlisle et al., 2011; Chinnayakanahalli et al., 2011) and (ii) initial flow volume may influence the likelihood of climate-induced shifts between some aspects of flow regimes (e.g. perennial vs intermittent). We therefore developed a flow regime classification that was inspired by and similar to previous CONUS-wide classifications but which explicitly incorporated the absolute magnitude of flow.

\section{Data source and inclusion criteria}

We used long-term, daily flow measurements from 601 reference-condition stream sites (i.e. watersheds with minimal land use and streams with minimal flow alteration) contained in the GAGES (Falcone et al., 2010) data (refer to the Selection of stations section in the succeeding texts). These data were used to estimate values for several flow metrics that represented different aspects of a stream's flow regime.

\section{Selection of flow variables}

We selected 16 flow variables for use in our analyses that, based on previous studies, well characterized ecologically important differences in flow amongst streams (Table 1, Appendix A). We recognize that classification outcomes, as well as assessments and interpretation of the effects of climate change on flow regimes, can be sensitive to the selection of the specific flow variables used in analyses (Olden et al., 2012). However, the use of many (10-100 s) flow variables can also obscure the physical interpretation of analyses, and produce classifications that may not match well with research or management objectives. Our view is that useful classifications should be both informed by theory and easily interpreted. We therefore selected a relatively small set of flow variables that collectively spanned the major dimensions of 
streamflow variation that ecologists view as important in maintaining stream ecosystem structure and function. We also choose not to differentially weight variables, because we have little a priori knowledge regarding the specific flow dependencies of different aquatic species and ecological processes. During variable selection, we tried to avoid excessive statistical redundancy amongst variables included in the analyses (correlations amongst variables are shown in Appendix A). We also found that the selection of specific variables to use in analyses was not always straightforward, especially when either many variables were available that describe a single, major aspect of flow, or variables had nonintuitive or problematic statistical properties. The most prominent of these issues was the selection of the specific high-flow and low-flow variables to use.

Of the 23 high-flow condition variables listed by Olden and Poff (2003), we selected two that we thought collectively characterized the important aspects of high-flow conditions: bank full flow and average seven-day maximum flow. Bank full flow is of potential ecological importance because it is related to streambed mobilization, channel morphology, and flood plain connectivity —all of which are important to stream biota. Average seven-day maximum flow quantifies aspects of high-flow magnitude as well, but also incorporates duration of sustained high flows.

Nonintuitive associations between flow constancy, the base flow index (BFI), and the fraction of zero days (ZDF) made the selection of low-flow variables complicated. Although these three variables were somewhat correlated, many streams with high constancy values were intermittent and had a large number of days with zero flow. The association between these three variables missed characterizing the steadiness (constancy) of flow in large perennial streams that often have high BFI. We therefore developed an extended low-flow index (ELFI) calculated as 
BFI - ZDF, which describes a flow pattern that varies from many days of zero flow to high relative amounts of more constant base flow contributions to the stream (refer to Dhungel (2014) for details). Combining ZDF and BFI in this way also addressed a statistical problem in their normalization as both had multiple zero values. After combining BFI and ZDF into the ELFI, flow constancy loaded with flow predictability on a separate PC axis, a result that made more sense physically in that it quantified the constancy and generally higher overall predictability of flows in large perennial streams.

\section{Selection of stations}

To assess the effects of climate on natural flow patterns, we needed flow data from a set of streams that were least affected by human influence. GAGES (Falcone et al., 2010) contains US Geological Survey flow records for streams draining 6785 watersheds. Falcone et al. (2010) identified 1512 of these watersheds as being least influenced by human activity. We wanted to

compute naturally occurring streamflow metrics that were as robust as possible, so we used only the 601 of these 1512 sites that had 90\% complete flow records over a 45 -year period (1965 to 2010) for our analysis. These sites ranged from Strahler stream order 1 to 11, with a mean annual flow ranging from 0.03 to $245 \mathrm{~m} 3 / \mathrm{s}$ (Figure 1). The vast majority of the 601 sites were order five or less with a mean annual flow less than $10 \mathrm{~m} 3 / \mathrm{s}$. The findings of this study are therefore limited to this range of stream sizes. We do not consider this truncated representation of stream sizes as a significant limitation, because the vast majority of streams in the USA fall into this group. 
Flow, watershed, and climate data

We assembled flow, watershed, and climate data for the 601 sites. Daily flow records were obtained from the US Geological Survey National Water Information System, and used to compute the 16 flow regime variables. TauDEM, a set of GIS terrain analysis software tools (Tarboton, 2005), was used to delineate the watersheds for these sites. We then computed 51 watershed and climate attributes for these watersheds (Appendix B) for use in predicting flow regime class. We followed (Sanborn and Bledsoe, 2006; Chinnayakanahalli, 2010) in using monthly climate data in these analyses. Historic monthly climate data were assembled from the Parameter-elevation Regression on Independent Slope Model (PRISM) dataset (Daly et al., 1994). Short-duration streamflow properties are responsive to short-term weather processes, but the limited availability of these data precluded their use in our analyses.

\section{Identifying independent dimensions of flow regimes with principal component analysis}

We used PCA to identify the main independent dimensions of flow variation amongst sites. We applied PCA with varimax rotation to the matrix of pairwise correlations between different flow variables following procedures detailed by Jackson (1991). In ideal applications of PCA, all associations between variables are linear, and variables are normally distributed (McCune et al., 2002). However, Q-Q plots and box plots showed that the distributions of most of the variables were non-normal, so we normalized those that required transformation with Box-Cox transformations. The parameter 'lamda' for the Box-Cox transformation was chosen to maximize the W-statistic in a Shapiro-Wilk normality test. Normality was achieved for all the variables except for the frequencies of low-flow events and zero-flow events, whose distributions were strongly influenced by clusters of zero values. Although we were not able to achieve 
complete normality for low-flow events and zero-flow events, we retained transformed versions of them in the analyses because they contain information on ecologically important aspects of flow not described by other variables. After transformation, all variables were standardized by subtracting their mean, and dividing by their standard deviation to equally weight their influence on PCs (Jackson, 1991). We used the 'principal' function from the 'psych' R library (Revelle, 2013) to perform the PC analysis. Following an initial PCA that identified only those PCs that had eigenvalues greater than 1 , we used varimax rotation to align the selected PCs along axes that maximized the correlation between original variables and PC factors. If any of the 16 variables had a loading less than 0.6 (a value we interpreted as indicating a strong loading) on any of the rotated PCs, we iteratively added components to the PCA based on their eigenvalues. We repeated this process until all of the 16 variables had a loading greater than 0.6 on one of the rotated PCs. This process resulted in a matrix of factor scores, F, with a dimension of 601 sites by five PCs.

\section{Flow regime classification}

We followed Olden et al. (2012) in using Ward's method of hierarchical, agglomerative clustering (Ward and Hook, 1963) to create a dendrogram that identified similarity amongst sites in flow patterns as measured by associations amongst sites in the five PC factor scores. We used the 'hclust' function in the R stats library (R Development Core Team, 2009) to conduct this analysis with Euclidean distance as the measure of similarity between sites or groups of site. Many approaches can be used to create classifications (Olden et al., 2012; McManamay et al., 2012), and the choice of method can affect classification outcomes. However, Ward's classification with Euclidean distances is one of the most widely used methods, and produces more realistic classifications than many other methods (McCune et al., 2002; Olden et al., 2012). 
Unlike nonhierarchical classification methods such as K-means (MacQueen, 1967), where the number of classes must be specified a priori, in Ward's method, the number of classes is selected based on a post-hoc interpretation of the dendrogram's structure. Ward's method was therefore useful in that the selection of specific clusters could be guided by our ability to physically interpret them.

\section{Random Forest stream class prediction model}

We used random forest (RF) (Breiman, 2001) to statistically model the probability of flow regime class membership as a function of climate and watershed properties. RF creates many classification trees by iteratively sampling a random fraction of the calibration data, and creating classification trees from each sample. Prediction is then based on a majority vote across the many classification trees. Model error was quantified by comparing out-of-bag predictions (i.e. withheld observations) for each site with the original classification.

For this model, we used 34 climate, 7 soil, and 10 topographic and geomorphology candidate predictor variables (Appendix B). For climate variables, we used the PRISM dataset (Daly et al., 1994). For soil variables, we used soil attributes from the State Soil Geographic dataset (Wolock, 1997). We used the Multi-Watershed Delineation tool (Chinnayakanahalli, 2010) to delineate watersheds from digital elevation models obtained from the National Elevation Dataset along with stream network data. The Multi-Watershed Delineation tool uses TauDEM (Tarboton, 2005) and ArcGIS functionality to delineate watersheds and derive watershed topographic attributes.

Prediction of flow regime class change in response to climate change 
We generated 4-km resolution climate projections by combining dynamical and statistical climate downscaling techniques. We first used the Weather Research and Forecasting model (WRF; http://wrf-model.org/index.php) to dynamically downscale the $150-\mathrm{km}$ resolution projections generated by the NCAR Community Climate System Model version 3 produced for the IPCC 4th assessment (IPCC, 2007) based on the A2 emission scenario (Nakicenovic et al., 2000). The CCSM data were bias-corrected with National Centers for Environmental Prediction reanalysis data before they were dynamically downscaled to $50-\mathrm{km}$ resolution with the WRF model. Such bias corrections were performed with both statistical regression and atmospheric equations to maintain physical consistency amongst the atmospheric variables such as temperature, humidity, geopotential height, and wind (refer to details in Meyer and Jin, (2015)). The 50-km resolution WRF precipitation and temperature projections were further downscaled with statistical regression to a 4-km spatial and 1 month temporal resolution based on the PRISM data (Daly et al., 1994). Use of monthly climate data avoids uncertainties introduced as a result of poor climate model reproduction of high-frequency weather. The statistical downscaling based on PRISM adjusts for orographic effects that are not well captured in coarse-resolution climate models. These forecasts were the same as used by Hill et al. (2014), who provide comparisons of these predictions with those of other combinations of global and regional climate models. Climate conditions were projected for the years 2001-2010 and 2090-2099 (referred hereafter as the 2000s and 2090s respectively). These 4-km climate projections were then aggregated over the watersheds of each site to describe watershed-scale climate, which were then used in the RF model to predict changes in flow regime classes. 


\section{RESULTS}

\section{Major attributes of flow regimes}

The PCA identified five major axes of flow variability across the study basins. The application of Kaiser's rule (PC eigenvalues greater than 1) (Kaiser, 1958) resulted in an initial selection of four PCs, but predictability and contingency had loadings less than 0.6. Adding a fifth PC resulted in all 16 flow variables having loadings greater than 0.6 , and $86 \%$ of the total variance present in the original 16 flow regime variable was associated with the five PCs (Table 1). The pattern of loadings of the 16 flow variables on the five PCs was intuitive and physically interpretable. The first PC represented variation amongst basins in low flows. The other components represented variation in overall magnitude, flashiness, timing, and constancy of flow.

\section{Classification of flow regimes}

We identified three distinct classes of streamflow regime (A, B, and C) as well as eight more finely resolved subclasses (Figure 2). The classes differed from one another in one or more flow factors as indicated by both box plots showing the distribution of PCA factor scores within classes (Figure 3) and daily flow patterns for representative streams in each class (Figure 4). The seasonal pattern of snowmelt-driven flow, characterized by low flashiness, was the primary factor associated with class A. Classes B and C had flashier flows, but differed in terms of the extended low-flow index, which separated intermittent streams (B) from perennial streams (C). Within the snow-fed streams (A), magnitude of flow distinguished A1 (small) from A2 (large) streams. Within intermittent streams (B), B1 streams were smaller with more extended periods of no flow than B21 and B22 streams. B21 and B22 streams differed in terms of whether flows occurred primarily in winter (B21) or summer (B22). Within the perennial streams (C), C1 
streams had early (winter) timing and more constant flows than C21 and C22 streams, which had a more seasonal pattern. C21 and C22 streams differed in size. C21 streams had smaller flows than C22 streams. We thus interpreted the eight stream classes to represent the following flow regimes: (A1) smaller perennial snow-fed streams, (A2) larger perennial snow-fed steams, (B1) smaller intermittent streams, (B21) larger intermittent streams with winter flow, (B22) larger intermittent streams with summer flow, (C1) perennial streams with mostly winter flow, (C21) smaller perennial streams with nonseasonal flow, and (C22) larger perennial streams with nonseasonal flow.

Spatial structure was evident for some of the classes (Figure 5). Classes A1 and A2 streams were found mostly in the north mid-western USA, with larger (A2) streams occurring in the northern part of the USA, and smaller (A1) streams occurring more in the south. Class B1 streams dominated the xeric areas of North and South Dakota as well as southern parts of California and Arizona. Class B22 streams occurred mostly in the central USA and across parts of Texas. B21 streams occurred mostly in the central part of the eastern USA. Sites belonging to class C1 occurred along the northwestern coast of the USA. Class C21 occurred along the Appalachian Mountains and in the Northeastern USA. Streams in Class C22 did not have an obvious spatial structure, but mainly occurred in different regions within the northern USA.

\section{Random forest model predictions of flow regime class}

Seven predictor variables were selected from the watershed and climate attributes listed in Appendix B for use in the random forest model to predict flow regime classes. The variables selected by the model were watershed area (AREA), percentage of precipitation that occurs when mean air temperature is less than zero (assumed to be snow) (PREC_SNM), the difference 
between mean annual maximum and mean annual minimum precipitation (DIFF_P), soil permeability (PRMH_AVE), proportion of annual precipitation that occurs in June (PRECIP_Jun_SC), mean elevation of the watershed (ELEV_MEAN), and proportion of annual precipitation that occurs in October (PRECIP_Oct_SC). The overall prediction (misclassification) error of the model was about 25\%, but varied amongst classes (Table 2) ranging from 14\% (Class C21) to 43\% (Class B21) (cf., Figure 5 and Figure 6 (top)). The larger error for class B indicates that the model is not able to predict aspects of low flow as well as other flow attributes.

\section{Predicted changes in flow regime classes in the 2090s}

The likelihood of streams changing flow regime class in response to projected climate change depended on the initial regime class (Table 3). The smallest per cent of sites were predicted to change class in the perennial snow-fed stream classes (A1 and A2). The highest per cent of class changes were predicted for intermittent streams with winter flows (B21) and intermittent streams with summer flows (B22), for which more than $50 \%$ of sites were predicted to change class. Many intermittent streams with winter flows (B21) were predicted to change to either intermittent streams with summer flows (B22) or small perennial streams (C21). Many intermittent streams (B21 and B22) were predicted to become perennial streams (C classes). 10\% of perennial streams (C classes) were predicted to become intermittent (B class streams).

Predicted changes in flow regime also showed a spatial pattern (Figure 6). Many predicted flow regime changes occurred across Nebraska, Kansas, the Dakotas, central Texas, the eastern part of Kentucky, and in central Virginia, where many intermittent streams (B classes) were predicted to change into perennial rain-fed streams (C classes). Many currently 
perennial streams (C classes) in South Dakota, in and around North Carolina, and in parts of Illinois and Indiana were predicted to change into intermittent (B classes) streams. Along with these major class changes, in which stream permanence changed, more subtle changes were predicted to occur in some of the more finely resolved stream classes. Some intermittent streams with winter flow (B21 classes) around the southern parts of Indiana were predicted to change to intermittent streams with summer flow (class B22). Similarly, some intermittent streams with summer flow (B22 class) in the central Texas region were predicted to change to small intermittent streams (B1 class). Subtle changes in timing and magnitude of some perennial streams were also predicted. Perennial streams with winter flows (C1 class) were predicted to change to smaller perennial streams with less-seasonal flows (C21 class) around the coast of Louisiana along with some sites around the southwestern edge of North Carolina. Many small perennial streams with nonseasonal flows (C21 class) were predicted to change to perennial streams with primarily winter flows (C1 class) around West Virginia and Connecticut. Some larger perennial streams (C22 class) were predicted to change to perennial streams with primarily winter flows (C1 class) in West Virginia.

\section{DISCUSSION}

The usefulness of our analyses for ultimately understanding and predicting how stream ecosystems and their biota will respond to climate change depends on several assumptions and conditions. First, we assumed that the flow variables, and the regimes derived from them, are ecologically meaningful. Second, we assumed that the models we developed to predict how flow regimes vary with watershed attributes and current climate conditions are sufficient to adequately describe important spatial variation amongst streams in their flow regimes. Third, we assumed that the climate models we used produced a reasonably plausible representation of future climate 
conditions in the CONUS. Finally, we assumed that the predictions from the empirical watershed-climate-flow model were informative of future flow regimes, recognizing the inevitable uncertainties in these predictions. We address each of these issues in detail below.

\section{Relevance of streamflow variables and regimes (assumption 1)}

The utility of our analyses for subsequent ecological assessments depend on how ecologically meaningful our characterizations of flow regimes were. We faced two conceptual and methodological challenges in this respect: (i) choice of the flow variables to include in analyses; and (ii) how to meaningfully characterize flow regimes as the simultaneous, multivariate variation in those flow variables across sites. Given that the specific flow dependencies of most stream species are unknown, we used insights from previous ecohydrological studies and discussion with stream ecology colleagues to select the 16 flow variables we used in the analyses. Each of these variables has been identified in the literature as being important to at least one species or functional process, and collectively, they characterize the main ecologically important dimensions of streamflow and are consistent with the flow variables used in other analyses (McCargo and Peterson, 2010; Chinnayakanahalli et al., 2011; Rolls et al., 2012). The use of only 16 key variables produced classifications that were qualitatively similar to the classifications produced by others based on a larger number of flow variables (Reidy Liermann et al., 2012; McManamay et al., 2014; Leasure et al., 2016) . Moreover, restricting our analyses to a manageable number of variables facilitated the interpretation of the PCA and classification results. This physical interpretation guided iterative addition, combination, and removal of variables to arrive at the final set of variables that we used. 
Prediction of flow regime class from watershed and climate variables (assumption 2)

We demonstrated that the flow regime classes we identified can be predicted from watershed and climate variables. Others have previously developed models to predict flow regime from watershed and climate variables (Sanborn and Bledsoe, 2006; Chinnayakanahalli et al., 2011; Reidy Liermann et al., 2012), but only Reidy Liermann et al. have used modelled climate data to predict flow regime class, albeit at a regional scale. Our modelling indicated that we could predict the natural streamflow regime classes with a mean accuracy of $75 \%$ with a small set of seven climate, geomorphological, and watershed soil variables. The random forest modelling approach we used successfully predicted smaller, snow-fed streams with high accuracy, but did not perform as well for intermittent and rain-fed streams.

The spatial structure of the flow classes we derived appears to be consistent with wellestablished spatial variation in climatic conditions across the CONUS, although classes were not geographically distinct. Some regions have a number of different stream classes intermingled and in close proximity. This intermingling was expected, given our reliance on magnitude variables, because streams vary in size regardless of climate and geological differences. The influence of geological differences on flows in close proximity has been noted by others (Poff, 1996; McManamay et al., 2012; Reidy Liermann et al., 2012; Eng et al., 2015). The fact that flow size variables were major discriminators in going from 3 to 8 classes in the hierarchical classification demonstrates that stream size is an important attribute in our classification. We think that including magnitude in the classification of flow regimes is important, given the importance of flow volume to stream biota and the likelihood that climate change will affect the magnitude of flow in some streams. Our results also imply that streams with larger discharges may be less vulnerable to climate change than smaller streams. 
These types of models have application beyond our primary objective (predicting the potential effects of climate change on flow regime at our study sites) in that they can predict the flow regimes of ungauged sites anywhere within the CONUS where watershed and climate attributes can be quantified. Given the importance of flow to stream ecosystems and the need to assess the status of environmental and ecological conditions of streams and rivers, there is a critical need to predict the natural flow regimes that characterize the millions of ungauged reaches in the USA and elsewhere (Poff et al., 2009; Hawkins et al., 2010; Chinnayakanahalli et al., 2011; Carlisle et al., 2014; Tonkin et al., 2014).

Future predictions of flow regime classes (assumptions 3 and 4)

The degree to which of our predictions of future flow regimes were realistic depends on two aspects of our modelling. First, the climate projections we used, originating in general circulation models, have known biases, which contribute to uncertainty in model predictions. We used statistical approaches to reduce the effect of these biases (Meyer and Jin, 2015), but such approaches cannot completely remove all the biases. Second, lack of stationarity in hydrologic systems has cast doubt on the use of stationary empirical models (Milly et al., 2008). This uncertainty propagates into the prediction of flow regimes. We recognize that this uncertainty affects the accuracy of the climate projections within the CONUS, and that the robustness of our results must be interpreted in the context of these uncertainties (Hill et al., 2014). These uncertainties appear to be highest when predicting the flow regimes of streams that are near the transition between perennial and permanent flows. There were both more uncertainty and more predicted class change in intermittent and rain-fed streams than snow-fed streams. These differences imply that the seasonal regime of snow-fed streams will be more robust to climate change than other types of regimes at the level of classification used here. Further work that 
identifies variables that discriminate subtler aspects of snow-fed flow regime may be needed to better understand the potential for change in snow-fed systems.

Our study anticipates that a number of changes in flow regime classes associated with predicted climate change by the end of the century will occur. For example, flow regimes in the central and eastern part of the USA were predicted to be more likely to change than those in the western USA. Specifically, a considerable proportion of intermittent streams in central USA (B21 and B22) and eastern USA (B21) were predicted to change into perennial type (Class C). These predictions for some currently intermittent streams to become perennial and vice versa are consistent with other climate model predictions that predict that temperatures will increase in both the north-central and eastern parts of the USA, whereas precipitation is projected to increase in just the eastern USA (IPCC, 2013). The prediction that many currently intermittent streams could switch to perennial status is important because considerable concern currently exists regarding the tendency for historically perennial streams to become intermittent as a result of both direct extraction and groundwater pumping (Larned et al., 2010). Moreover, we know considerably less about either the hydrology or ecology of historically intermittent streams than perennial streams simply because they have been less studied than permanent streams (Eng et al., 2015; Cid et al., 2016). Our results identify a potential pattern in how streamflows may respond to climate change that, to our knowledge, has not been identified or emphasized by other studies.

Our results indicate that in western mountainous regions, the snow-fed regimes of many streams may be relatively insensitive to climate change, at least in terms of the flow regime classes used here. These results are consistent with analyses conducted by (Poff et al., 1996) who showed that rainfall-driven flow regimes were more sensitive to climate change than snowmelt regimes, but they contrast with those of (Reidy Liermann et al., 2012) who predicted that many 
streams in Washington state would shift from snow-fed dominated streams to rain-fed streams by 2040s with an accompanying reduction in annual discharge. However, our results are not directly comparable with (Reidy Liermann et al., 2012) because they used a different climate change scenario. Their study also focussed on a smaller area in which precipitation appears to be especially vulnerable to shifts from snow to rain. Although our results indicate that the effects of climate alone on the seasonal nature and pattern of streamflow may not greatly alter streamflow regimes across the mountainous areas of the western USA as a whole, further work that identifies variables that discriminate subtler aspects of snow-fed flow regime may be needed to better understand the potential for change in snow-fed systems. Also, the pervasive presence of land use in most watersheds (Falcone et al., 2010) will most likely interact with climate change to influence streamflow regimes (Ordonez et al., 2014; Kuemmerlen et al., 2015).

\section{CONCLUSIONS}

We conducted these analyses to better understand the likely hydrological consequences of climate change for stream biota and their ecosystems, a general concern amongst stream ecologists (Palmer et al., 2008; Tonkin et al., 2014). Given the uncertainty in the magnitude of future emissions of greenhouse gases and differences between climate models in their specific predictions, it is impossible to predict with certainty how the flow regimes in streams of the USA and elsewhere will change. However, our study indicates that climate-induced changes in streamflow are likely to be both significant and variable across the USA. Improving our understanding of what specific types of streams will be most vulnerable to climate change, and how climate-induced changes in flow regimes will affect stream ecosystem structure and function is a critical research priority. The streamflow regime classification we developed allowed us to characterize streamflow regimes at the scale of the CONUS, was physically 
interpretable, and was sufficiently resolved that we could assess how different streamflow regimes may change in response to projected climate changes. The explicit choice to include flow magnitude as a classification variable helped reveal that stream size is likely to influence the vulnerability of individual streams to climate change. In a following paper, we will describe how these projected shifts in flow regimes are predicted to affect the biodiversity patterns of stream invertebrates.

\section{ACKNOWLEDGEMENTS}

This research received support from grant (RD834186) from the US Environmental Protection Agency's National Center for Environmental Research (NCER) Science to the Achieve Results (STAR) program. We thank LeRoy Poff and an anonymous reviewer for their comments and suggestions, which greatly improved the manuscript. 


\section{REFERENCES}

Anderson EP, Freeman MC, Pringle CM. 2006. Ecological consequences of hydropower development in Central America: impacts of small dams and water diversion on neotropical stream fish assemblages. River Research and Applications 22: 397-411. DOI: 10.1002/rra.899.

Archfield SA, Kennen JG, Carlisle DM, Wolock DM. 2013. An objective and parsimonious approach for classifying natural flow regimes at a continental scale. River Research and Applications. DOI: 10.1002/rra.2710.

Arnell NW, Gosling SN. 2013. The impacts of climate change on river flow regimes at the global scale. Journal of Hydrology 486: 351-364. DOI: 10.1016/j.jhydrol.2013.02.010.

Bachelet D, Neilson RP, Lenihan JM, Drapek RJ. 2001. Climate change effects on vegetation distribution and carbon budget in the United States. Ecosystems 4: 164-185. DOI: 10.1007/s10021-001-0002-7.

Breiman L. 2001. Random forests. Machine Learning 45: 5-32. DOI: 10.1023/a:1010933404324. Brutsaert W 2005. Hydrology: An Introduction. Cambridge University Press

Carlisle DM, Wolock DM, Meador MR. 2011. Alteration of streamflow magnitudes and potential ecological consequences: a multiregional assessment. Frontiers in Ecology and the Environment 9: 264-270. DOI: 10.1890/100053.

Carlisle DM, Nelson SM, Eng K. 2014. Macroinvertebrate community condition associated with the severity of streamflow alteration. River Research and Applications 30: 29-39. DOI: 10.1002/rra.2626.

Chang H, Jung I-W. 2010. Spatial and temporal changes in runoff caused by climate change in a complex large river basin in Oregon. Journal of Hydrology 388: 186-207. DOI: 10.1016/j.jhydrol.2010.04.040.

Chinnayakanahalli K 2010, Characterizing ecologically relevant variations in streamflow regimes, Ph.D. thesis, 221 pp., Utah State University, Logan, http://digitalcommons.usu.edu/etd/561

Chinnayakanahalli KJ, Hawkins CP, Tarboton DG, Hill RA. 2011. Natural flow regime, temperature and the composition and richness of invertebrate assemblages in streams of the western United States. Freshwater Biology 56: 1248-1265. DOI: 10.1111/j.13652427.2010.02560.x.

Christensen NS, Wood AW, Voisin N, Lettenmaier DP, Palmer RN. 2004. The effects of climate change on the hydrology and water resources of the Colorado River Basin. Climatic Change 62: 337-363. DOI: 10.1023/B:CLIM.0000013684.13621.1f.

Cid N, Verkaik I, García-Roger EM, Rieradevall M, Bonada N, Sánchez-Montoya MM, Gómez R, Suárez ML, Vidal-Abarca MR, Demartini D, Buffagni A, Erba S, Karaouzas I, Skoulikidis N, Prat N. 2016. A biological tool to assess flow connectivity in reference temporary streams from the Mediterranean Basin. Science of The Total Environment 540: 178-190. DOI: 10.1016/j.scitotenv.2015.06.086.

Daly C, Neilson RP, Phillips DL. 1994. A statistical-topographic model for mapping climatological precipitation over mountainous terrain. Journal of Applied Meteorology 33: 140-158. DOI: 10.1175/1520-0450(1994)033<0140:ASTMFM>2.0.CO;2.

Dhungel S 2014, Prediction of climate change effects on streamflow regime important to stream ecology, 124 pp., Utah State University, Logan, http://digitalcommons.usu.edu/etd/3083

Dingman SL 2002. Physical Hydrology. Prentice Hall 
Döll P, Zhang J. 2010. Impact of climate change on freshwater ecosystems: a global-scale analysis of ecologically relevant river flow alterations. Hydrology and Earth System Sciences 14: 783-799. DOI: 10.5194/hess-14-783-2010.

Eng K, Wolock DM, Dettinger MD. 2015. Sensitivity of intermittent streams to climate variations in the USA. River Research and Applications. DOI: 10.1002/rra.2939.

Falcone JA, Carlisle DM, Wolock DM, Meador MR. 2010. GAGES: a stream gage database for evaluating natural and altered flow conditions in the conterminous United States. Ecology 91: 621-621. DOI: 10.1890/09-0889.1.

Freeman M, Marcinek P. 2006. Fish assemblage responses to water withdrawals and water supply reservoirs in Piedmont streams. Environmental Management 38: 435-450. DOI: 10.1007/s00267-005-0169-3.

Hauer FR, Baron JS, Campbell DH, Fausch KD, Hostetler SW, Leavesley GH, Leavitt PR, McKnight DM, Stanford JA. 1997. Assessment of climate change and freshwater ecosystems of the rocky mountains, USA and Canada. Hydrological Processes 11: 903924. DOI: 10.1002/(sici)1099-1085(19970630)11:8<903::aid-hyp511>3.0.co;2-7.

Hawkins CP, Olson JR, Hill RA. 2010. The reference condition: predicting benchmarks for ecological and water-quality assessments. Journal of the North American Benthological Society 29: 312-343. DOI: 10.1899/09-092.1.

Held IM, Soden BJ. 2006. Robust responses of the hydrological cycle to global warming. Journal of Climate 19: 5686-5699. DOI: 10.1175/JCLI3990.1.

Hill R, Hawkins C, Jin J. 2014. Predicting thermal vulnerability of stream and river ecosystems to climate change. Climatic Change 125: 399-412. DOI: 10.1007/s10584-014-1174-4.

IPCC 2007, Climate Change 2007: The Physical Science Basis. Contribution of Working Group I to the Fourth Assessment Report of the Intergovernmental Panel on Climate Change [Solomon, S., D. Qin, M. Manning, Z. Chen, M. Marquis, K.B. Averyt, M.Tignor and H.L. Miller (eds.)]. Cambridge University Press, Cambridge, United Kingdom and New York, NY, USA., https://www.ipcc.ch/publications and data/ar4/wg1/en/contents.html

IPCC 2013, Summary for Policymakers, in Climate Change 2013: The Physical Science Basis. Contribution of Working Group I to the Fifth Assessment Report of the Intergovernmental Panel on Climate Change, edited by T. F. Stocker, D. Qin, G.-K. Plattner, M. Tignor, S. K. Allen, J. Boschung, A. Nauels, Y. Xia, V. Bex and P. M. Midgley, pp. 1-30, Cambridge University Press, Cambridge, United Kingdom and New York, NY, USA.

Jackson JE 1991. A user's guide to principal components. John Wiley and Sons, Inc.: New York

Jung I-W, Moradkhani H, Chang H. 2012. Uncertainty assessment of climate change impacts for hydrologically distinct river basins. Journal of Hydrology 466-467: 73-87. DOI: 10.1016/j.jhydrol.2012.08.002.

Kaiser H. 1958. The varimax criterion for analytic rotation in factor analysis. Psychometrika 23: 187-200. DOI: $10.1007 / \mathrm{bf02289233.}$

Kuemmerlen M, Schmalz B, Cai Q, Haase P, Fohrer N, Jähnig SC. 2015. An attack on two fronts: predicting how changes in land use and climate affect the distribution of stream macroinvertebrates. Freshwater Biology 60: 1443-1458. DOI: 10.1111/fwb.12580.

Larned ST, Datry T, Arscott DB, Tockner K. 2010. Emerging concepts in temporary-river ecology. Freshwater Biology 55: 717-738. DOI: 10.1111/j.1365-2427.2009.02322.x.

Leasure DR, Magoulick DD, Longing SD. 2016. Natural flow regimes of the Ozark-Ouachita interior highlands region. River Research and Applications 32: 18-35. DOI: 10.1002/rra.2838. 
MacQueen J 1967, Some methods for classification and analysis of multivariate observations, paper presented at Proceedings of the Fifth Berkeley Symposium on Mathematical Statistics and Probability, Volume 1: Statistics, University of California Press, Berkeley, Calif.,281-297,http://projecteuclid.org/euclid.bsmsp/1200512992

Maurer EP, Duffy PB. 2005. Uncertainty in projections of streamflow changes due to climate change in California. Geophysical Research Letters 32. DOI: 10.1029/2004GL021462.

McCargo JW, Peterson JT. 2010. An evaluation of the influence of seasonal base flow and geomorphic stream characteristics on coastal plain stream fish assemblages. Transactions of the American Fisheries Society 139: 29-48. DOI: 10.1577/t09-036.1.

McCune B, Grace JB, Urban DL 2002. Analysis of Ecological Communities. MjM Software Design: Gleneden Beach, OR

McKay SF, King AJ. 2006. Potential ecological effects of water extraction in small, unregulated streams. River Research and Applications 22: 1023-1037. DOI: 10.1002/rra.958.

McManamay RA, Orth DJ, Dolloff CA, Frimpong EA. 2012. A regional classification of unregulated stream flows: spatial resolution and hierarchical frameworks. River Research and Applications 28: 1019-1033. DOI: 10.1002/rra.1493.

McManamay RA, Bevelhimer MS, Kao S-C. 2014. Updating the US hydrologic classification: An approach to clustering and stratifying ecohydrologic data. Ecohydrology 7: 903-926. DOI: $10.1002 /$ eco.1410.

McManamay RA, Bevelhimer MS, Frimpong EA. 2015. Associations among hydrologic classifications and fish traits to support environmental flow standards. Ecohydrology 8: 460-479. DOI: 10.1002/eco.1517.

Melack JM, Dozier J, Goldman CR, Greenland D, Milner AM, Naiman RJ. 1997. Effects of climate change on inland waters of the pacific coastal mountains and western great basin of North America. Hydrological Processes 11: 971-992. DOI: 10.1002/(sici)10991085(19970630)11:8<971::aid-hyp514>3.0.co;2-y.

Meyer JD, Jin J. 2015. Bias correction of the CCSM4 for improved regional climate modeling of the North American monsoon. Climate Dynamics: 1-16. DOI: 10.1007/s00382-015-27445.

Meyer JL, Sale MJ, Mulholland PJ, Poff NL. 1999. Impacts of climate change on aquatic ecosystem functioning and health. JAWRA Journal of the American Water Resources Association 35: 1373-1386. DOI: 10.1111/j.1752-1688.1999.tb04222.x.

Milly PCD, Betancourt J, Falkenmark M, Hirsch RM, Kundzewicz ZW, Lettenmaier DP, Stouffer RJ. 2008. Stationarity is dead: Whither water management? Science 319: 573574. DOI: $10.1126 /$ science. 1151915.

Mulholland PJ, Best GR, Coutant CC, Hornberger GM, Meyer JL, Robinson PJ, Stenberg JR, Turner RE, Vera-Herrera F, Wetzel RG. 1997. Effects of climate change on freshwater ecosystems of the south-eastern United States and the gulf coast of Mexico. Hydrological Processes 11: 949-970. DOI: 10.1002/(sici)1099-1085(19970630)11:8<949::aidhyp513>3.0.co;2-g.

Nakicenovic N, Alcamo J, Davis G, Vries Bd, Fenhann J, Gaffin S, Gregory K, Grübler A, Jung TY, Kram T, Rovere ELL, Michaelis L, Mori S, Morita T, Pepper W, Pitcher H, Price L, Riahi K, Roehrl A, Rogner H-H, Sankovski A, Schlesinger M, Shukla P, Smith S, Swart R, Rooijen Sv, Victor N, Dadi Z 2000, Emissions Scenarios, http://www.ipcc.ch/ipccreports/sres/emission/index.php?idp=115 
Nijssen B, O'Donnell G, Hamlet A, Lettenmaier D. 2001. Hydrologic sensitivity of global rivers to climate change. Climatic Change 50: 143-175. DOI: 10.1023/A:1010616428763.

Olden JD, Poff NL. 2003. Redundancy and the choice of hydrologic indices for characterizing streamflow regimes. River Research and Applications 19: 101-121. DOI: 10.1002/rra.700.

Olden JD, Kennard MJ, Pusey BJ. 2012. A framework for hydrologic classification with a review of methodologies and applications in ecohydrology. Ecohydrology 5: 503-518. DOI: $10.1002 /$ eco.251.

Ordonez A, Martinuzzi S, Radeloff VC, Williams JW. 2014. Combined speeds of climate and land-use change of the conterminous US until 2050. Nature Climate Change 4: 811-816. DOI: $10.1038 /$ nclimate2337.

Palmer MA, Reidy Liermann CA, Nilsson C, Flörke M, Alcamo J, Lake PS, Bond N. 2008. Climate change and the world's river basins: anticipating management options. Frontiers in Ecology and the Environment 6: 81-89. DOI: 10.1890/060148.

Poff NL, Ward JV. 1989. Implications of streamflow variability and predictability for lotic community structure: A regional analysis of streamflow patterns. Canadian Journal of Fisheries and Aquatic Sciences 46: 1805-1818. DOI: 10.1139/f89-228.

Poff NL. 1996. A hydrogeography of unregulated streams in the United States and an examination of scale-dependence in some hydrological descriptors. Freshwater Biology 36: 71-91. DOI: 10.1046/j.1365-2427.1996.00073.x.

Poff NL, Tokar S, Johnson P. 1996. Stream hydrological and ecological responses to climate change assessed with an artificial neural network. Limnology and Oceanography 41: 857863. DOI: 10.4319/lo.1996.41.5.0857.

Poff NL, Allan JD, Bain MB, Larr JR, Prestegaard KL, Richter BD, Sparks RE, Stromberg JC. 1997. The natural flow regime: a paradigm for conservation and restoration of river ecosystems. BioScience 47: 769-784. DOI: 10.2307/1313099.

Poff NL, Zimmerman JKH. 2009. Ecological responses to altered flow regimes: a literature review to inform the science and management of environmental flows. Freshwater Biology 55: 194-205. DOI: 10.1111/j.1365-2427.2009.02272.x.

Poff NL, Richter BD, Arthington AH, Bunn SE, Naiman RJ, Kendy E, Acreman M, Apse C, Bledsoe BP, Freeman MC, Henriksen J, Jacobson RB, Kennen JG, Merritt DM, O'Keeffe JH, Olden JD, Rogers K, Tharme RE, Warner A. 2009. The ecological limits of hydrologic alteration (ELOHA): A new framework for developing regional environmental flow standards. Freshwater Biology 55: 147-170. DOI: 10.1111/j.13652427.2009.02204.x.

R Development Core Team 2009, R: A language and environment for statistical computing, version 2.10.1, R Foundation for Statistical Computing, Vienna, Austria

Reidy Liermann CA, Olden JD, Beechie TJ, Kennard MJ, Skidmore PB, Konrad CP, Imaki H. 2012. Hydrogeomorphic classification of Washington state rivers to support emerging environmental flow management strategies. River Research and Applications 28: 13401358. DOI: 10.1002/rra.1541.

Revelle W 2013, psych: Procedures for psychological, psychometric, and personality research, version 1.3.2, Northwestern University, Evanston, IL. http://CRAN.Rproject.org/package $=$ psych 
Rolls RJ, Leigh C, Sheldon F. 2012. Mechanistic effects of low-flow hydrology on riverine ecosystems: ecological principles and consequences of alteration. Freshwater Science 31: 1163-1186. DOI: 10.1899/12-002.1.

Sanborn SC, Bledsoe BP. 2006. Predicting streamflow regime metrics for ungauged streams in Colorado, Washington, and Oregon. Journal of Hydrology 325: 241-261. DOI: 10.1016/j.jhydrol.2005.10.018.

Stewart IT, Cayan DR, Dettinger MD. 2004. Changes in snowmelt runoff timing in Western North America under a 'Business as usual' climate change scenario. Climatic Change 62: 217-232. DOI: 10.1023/B:CLIM.0000013702.22656.e8.

Tague C, Grant G, Farrell M, Choate J, Jefferson A. 2008. Deep groundwater mediates streamflow response to climate warming in the Oregon Cascades. Climatic Change 86: 189-210. DOI: $10.1007 / \mathrm{s} 10584-007-9294-8$.

Tarboton DG 2005, Terrain Analysis Using Digital Elevation Models (TauDEM), Utah Water Research Laboratory, Utah State University, $<$ http://www.engineering.usu.edu/dtarb $>$

Thodsen H. 2007. The influence of climate change on stream flow in Danish rivers. Journal of Hydrology 333: 226-238. DOI: 10.1016/j.jhydrol.2006.08.012.

Tonkin JD, Jähnig SC, Haase P. 2014. The rise of riverine flow-ecology and environmental flow research. Environmental Processes 1: 323-330. DOI: 10.1007/s40710-014-0024-8.

Tucker GE, Slingerland R. 1997. Drainage basin responses to climate change. Water Resources Research 33: 2031-2047. DOI: 10.1029/97WR00409.

Vannote RL, Minshall GW, Cummins KW, Sedell JR, Cushing CE. 1980. The river continuum concept. Canadian Journal of Fisheries and Aquatic Sciences 37: 130-137. DOI: 10.1139/f80-017.

Ward JH, Hook ME. 1963. Application of an hierarchical grouping procedure to a problem of grouping profiles. Educational and Psychological Measurement 23: 69-81. DOI: 10.1177/001316446302300107.

Wolock DM 1997, STATSGO soil characteristics for the conterminous United States, Lawrence, $\mathrm{KS}$,

Zhou S, Yuan X, Peng S, Yue J, Wang X, Liu H, Williams DD. 2014. Groundwater-surface water interactions in the hyporheic zone under climate change scenarios. Environmental Science and Pollution Research 21: 13943-13955. DOI: 10.1007/s11356-014-3255-3. 
Table 1. Loadings of the 16 Box-Cox transformed flow variables on 5 varimax-rotated principal components. Loadings with magnitude greater than 0.6 are indicated in bold.

\begin{tabular}{|c|c|c|c|c|c|}
\hline \multirow[b]{2}{*}{ Flow Variables } & \multicolumn{5}{|c|}{ Rotated Principal Components } \\
\hline & $P C 1$ & $P C 2$ & $P C 3$ & $P C 4$ & $P C 5$ \\
\hline Extended Low Flow Index (ELFI) & 0.83 & 0.05 & 0.05 & 0.15 & -0.14 \\
\hline Coefficient of Variation of Daily Flows (DAYCV) & -0.82 & -0.07 & 0.07 & 0.04 & 0.36 \\
\hline Contingency $(\mathrm{M})$ & 0.67 & -0.01 & -0.44 & -0.23 & 0.1 \\
\hline Low Flow Event Frequency (LFE) & 0.84 & 0.13 & 0.29 & 0.02 & -0.05 \\
\hline Zero Flow Event Frequency (ZFE) & -0.85 & -0.17 & -0.01 & 0.05 & 0.22 \\
\hline Average 7 day Minimum Flow (Qmin7) & 0.71 & 0.58 & 0.01 & 0.07 & -0.25 \\
\hline Mean daily discharge (QMEAN) & 0.31 & 0.93 & 0.03 & -0.08 & -0.14 \\
\hline Bank Full Flow (Q167) & 0.01 & 0.97 & 0.21 & -0.12 & 0 \\
\hline Average 7 day Maximum Flow (Qmax7) & 0.08 & 0.99 & 0.03 & -0.07 & -0.01 \\
\hline Flow Reversal(R) & 0.54 & 0.12 & 0.68 & 0 & -0.14 \\
\hline Flood Duration (FLDDUR) & 0.09 & -0.07 & -0.84 & 0.2 & 0.18 \\
\hline High Flow Event Frequency (HFE) & 0.02 & 0.1 & 0.91 & -0.22 & -0.07 \\
\hline $50 \%$ timing of flow (T50) & 0.04 & -0.11 & -0.36 & 0.79 & 0.2 \\
\hline Time of Peak (Tp) & -0.02 & -0.09 & -0.08 & 0.89 & -0.01 \\
\hline Predictability (P) & -0.3 & -0.08 & -0.36 & 0.05 & 0.86 \\
\hline Constancy $(\mathrm{C})$ & -0.56 & -0.11 & -0.1 & 0.2 & 0.73 \\
\hline Proportion of variance explained (cumulative) & 0.28 & $0.21(0.49)$ & $0.16(0.65)$ & $0.1(0.75)$ & $0.11(0.86)$ \\
\hline Interpretation & $\begin{array}{l}\text { Low Flow } \\
\text { (L) }\end{array}$ & $\begin{array}{l}\text { Magnitude } \\
\text { (Q) }\end{array}$ & $\begin{array}{c}\text { Flashiness } \\
\text { (F) }\end{array}$ & $\begin{array}{l}\text { Timing } \\
(\mathrm{T})\end{array}$ & $\begin{array}{c}\text { Constancy } \\
\text { (C) }\end{array}$ \\
\hline
\end{tabular}


Table 2. Out-of-bag random forest model confusion matrix showing prediction error for each flow regime class based on model calibration data for the period $1965-$ 2010

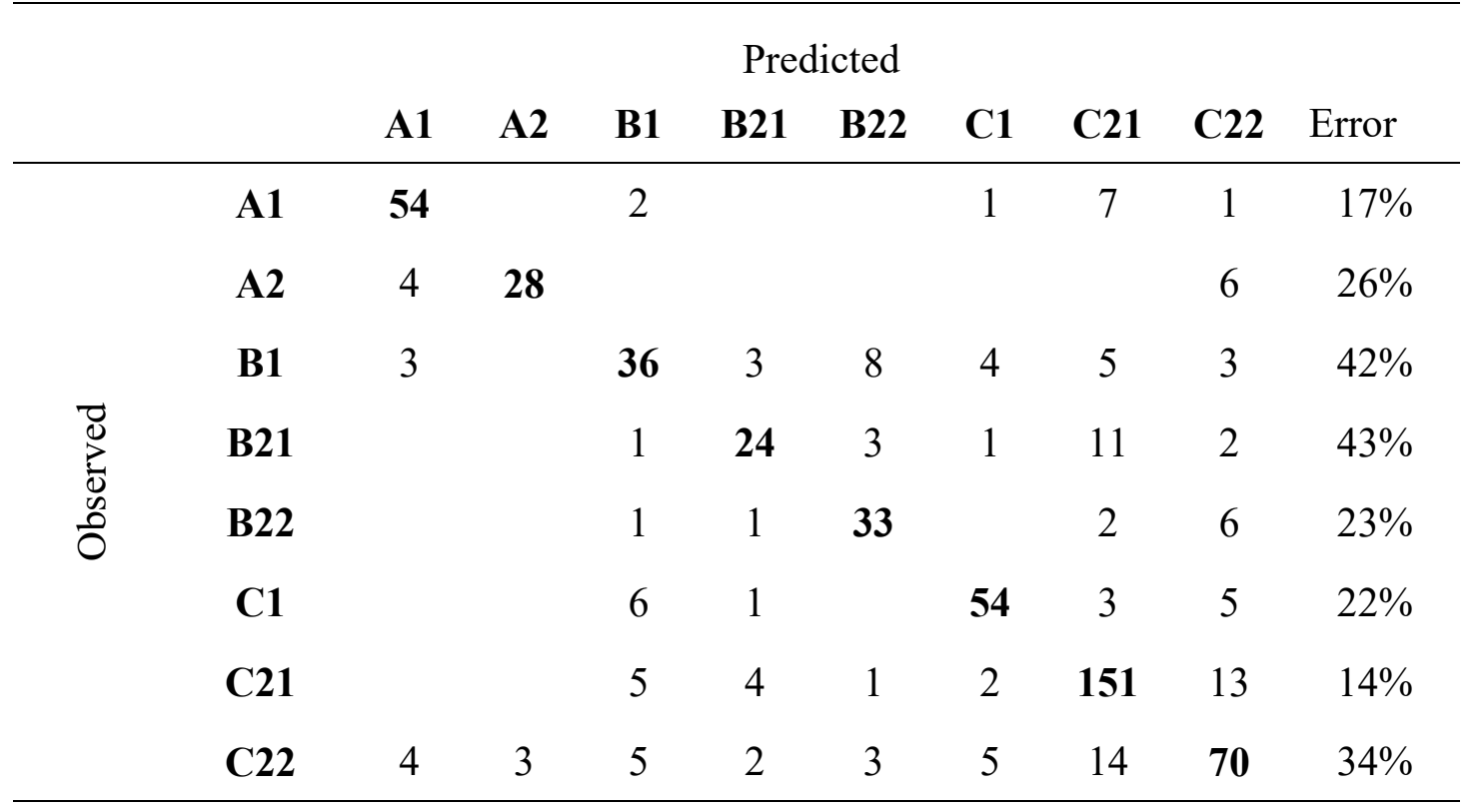

Table 3: Matrix showing predicted change (\%) in flow regime class between 2001-2010 and 2090-2099.

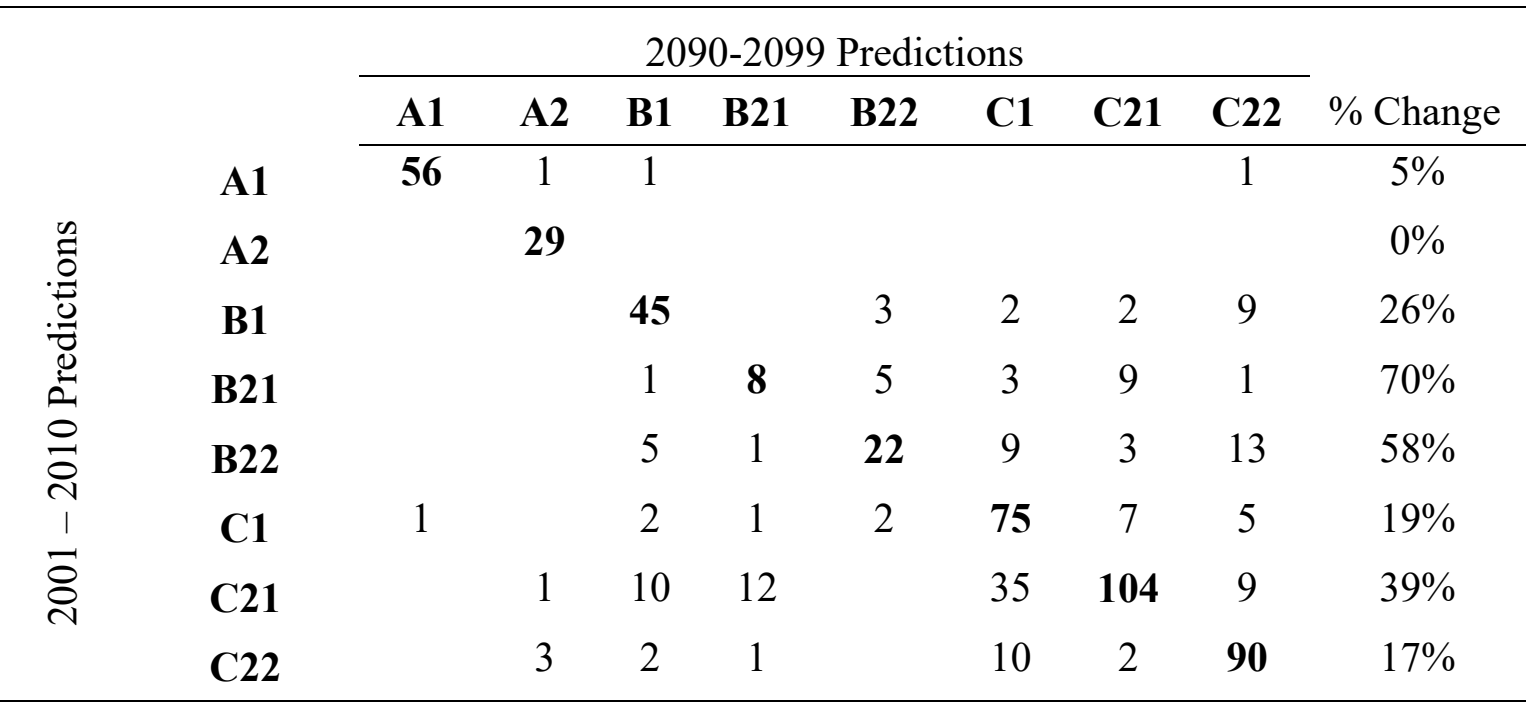




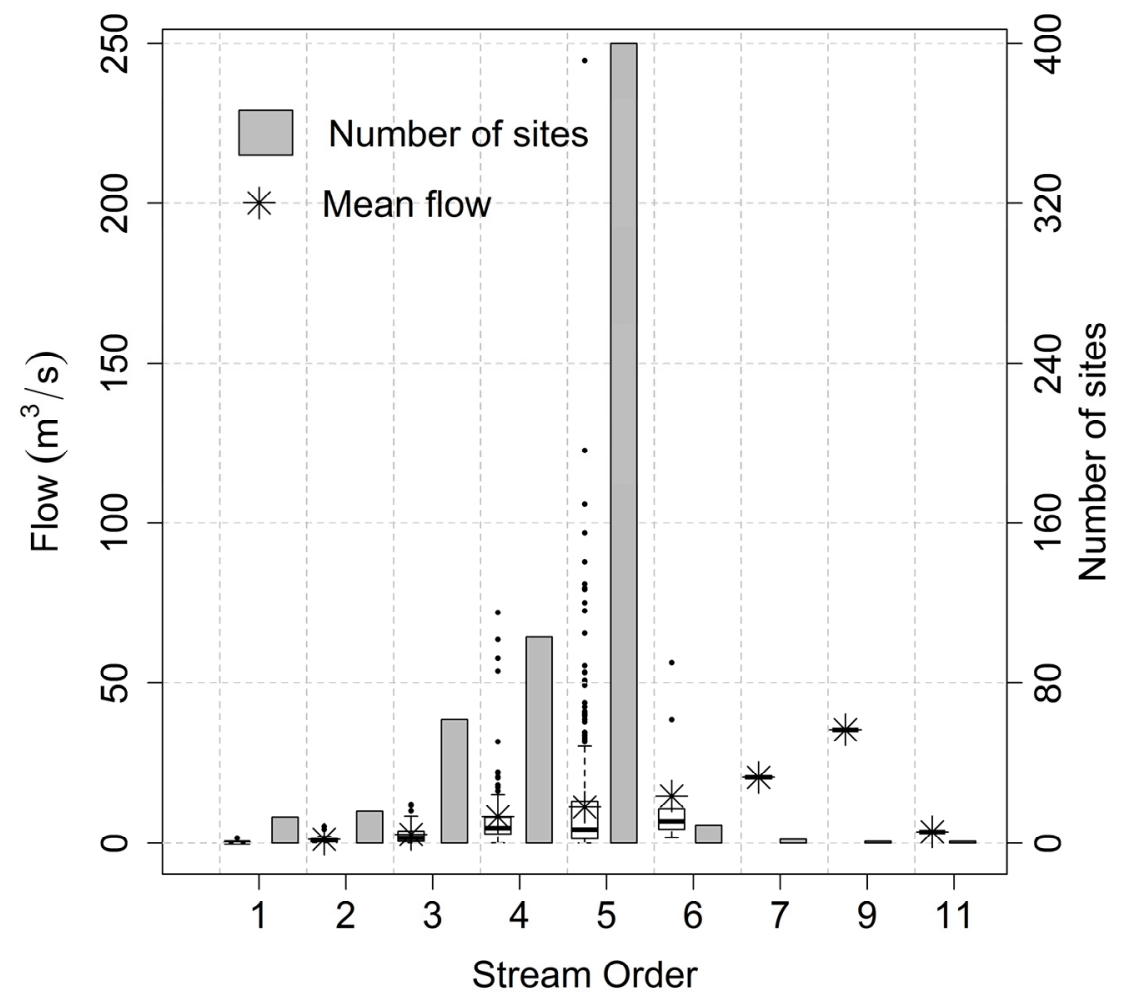

Figure 1. Ranges of mean annual flow and Strahler stream order across the study sites. 


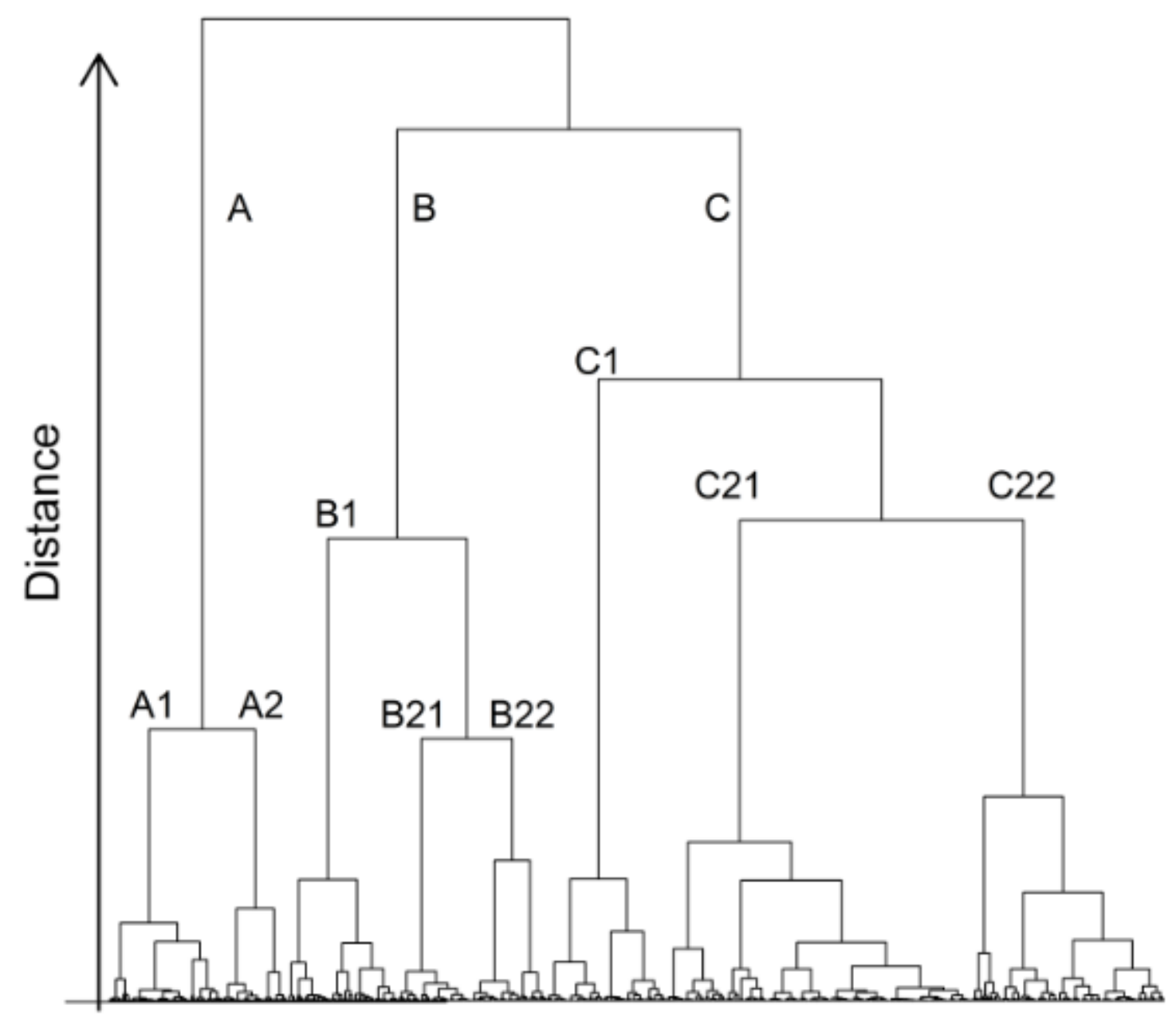

Figure 2. Classification dendogram. The eight classes are - (A1) small perennial snow fed streams, (A2) large perennial snowfed steams, (B1) small intermittent streams, (B21) intermittent streams with winter flow, (B22) intermittent streams with summer flow, (C1) perennial streams with winter flow, (C21) small perennial streams, and (C22) large perennial streams. 

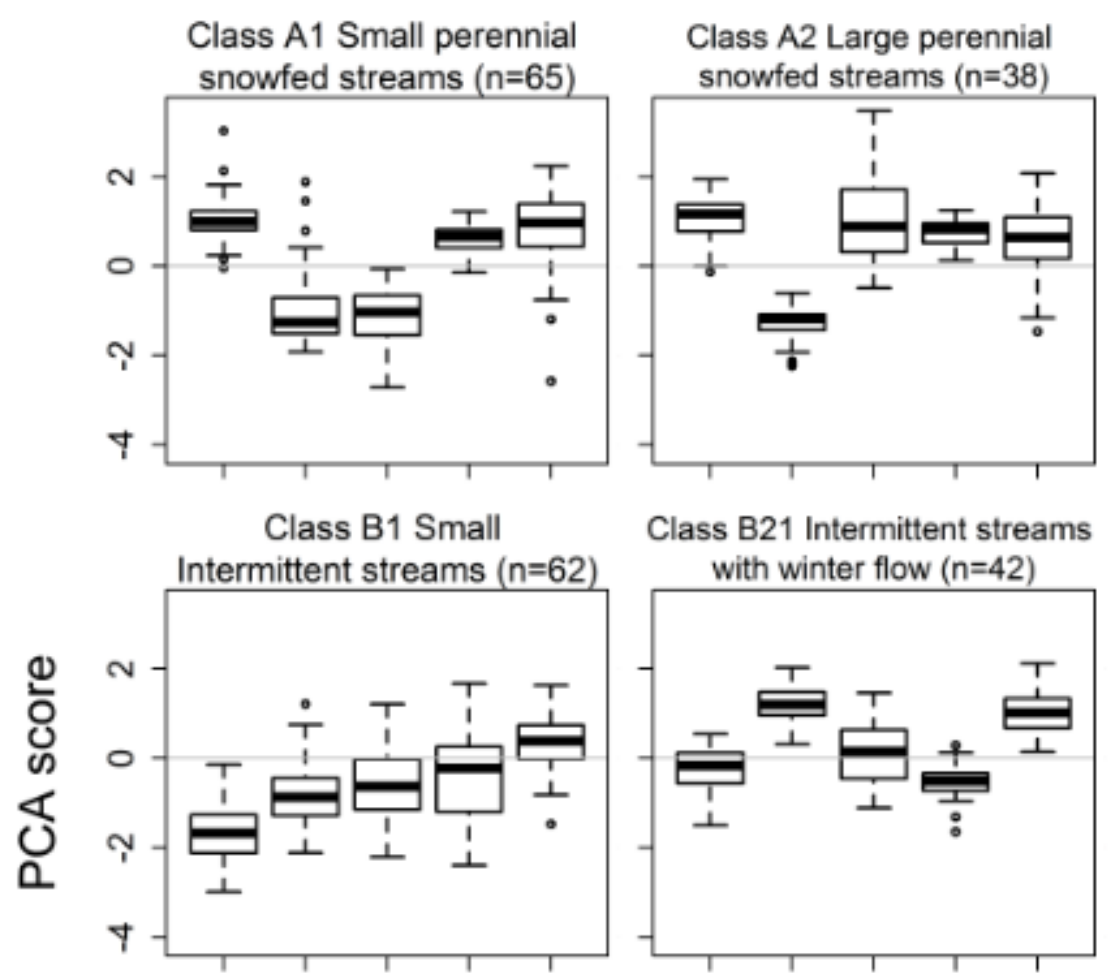

Class B21 Intermittent streams with winter flow $(n=42)$

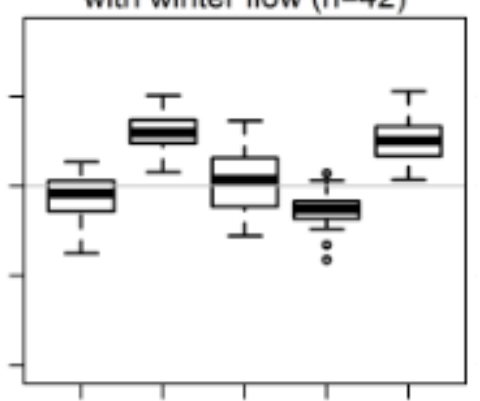

Class B22 Intermittent streams with summer flow $(n=43)$

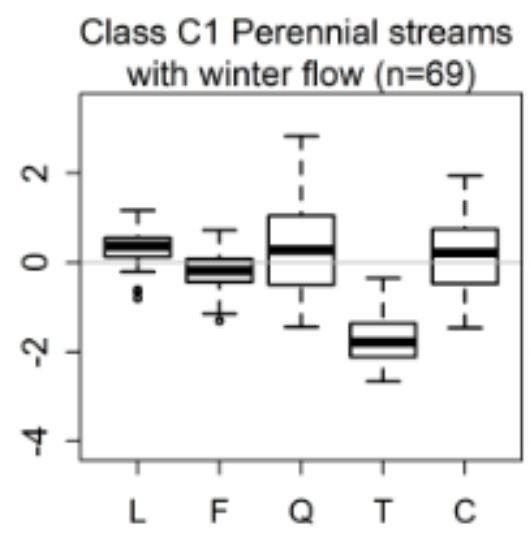

Class C21 Small perennial streams $(n=176)$
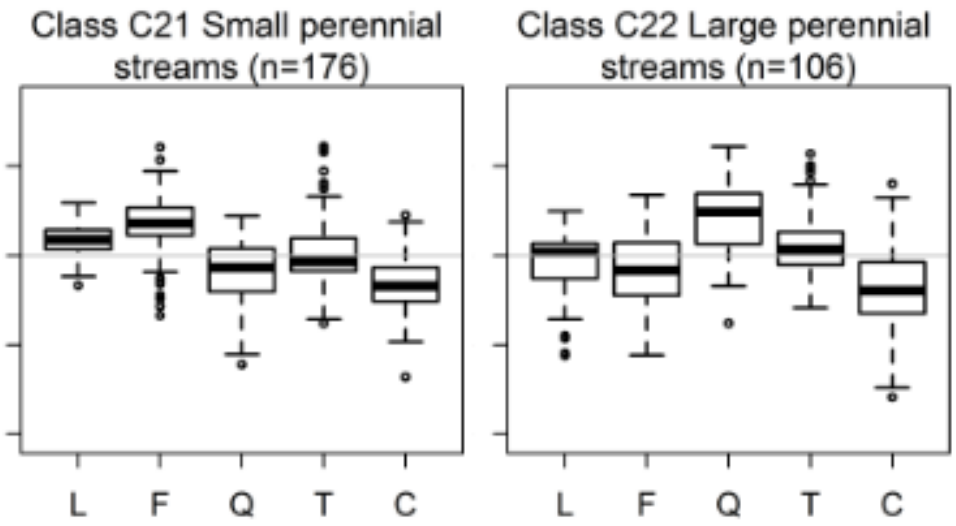

Flow Attributes

Figure 3. Box plots showing the distribution of varimax-rotated principal component factors for eight stream classes. The sample size (n) for each class is given. $\mathrm{X}$-axis labels indicate the varimax-rotated principal component factors from Table 1 with $\mathrm{L}=$ Low Flow, $\mathrm{F}=$ Flashiness, $\mathrm{Q}$ $=$ Magnitude, $\mathrm{T}=$ Timing, $\mathrm{C}=$ Constancy . 

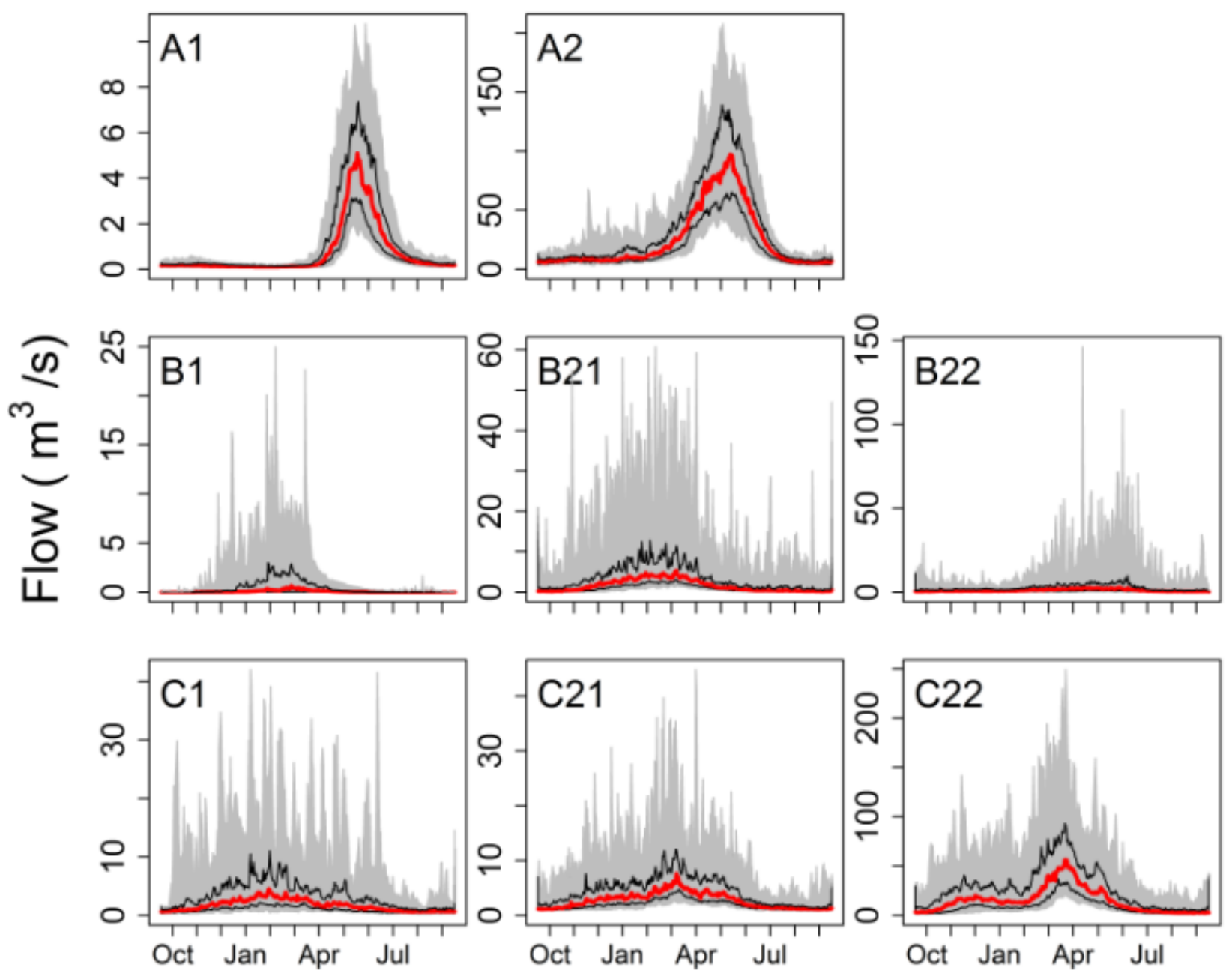

\section{Months}

Figure 4. Daily flow patterns for the archetypical stream in each class (i.e., the stream closest to the median of each of the PC factors). Gray shading gives the $5^{\text {th }}$ to $95^{\text {th }}$ percentile range of daily flows, fine lines give $25^{\text {th }}$ and $75^{\text {th }}$ percentile, and the bold (red) line gives the $50^{\text {th }}$ percentile (median). The stream closest to the median was determined using Euclidean distance computed in the PC factor space. 


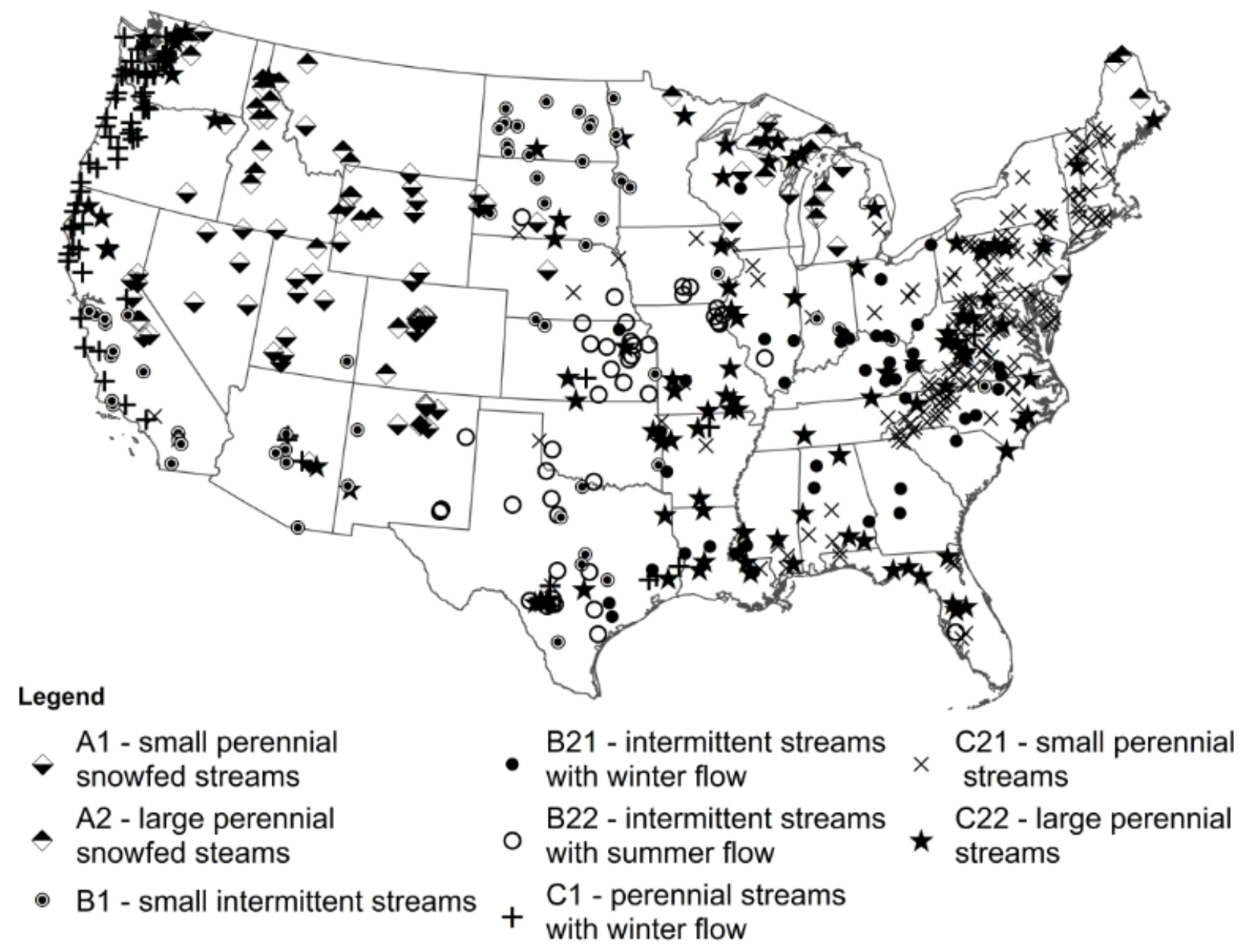

Figure 5. Spatial distribution of streams assigned to the 8 flow regime classes. 

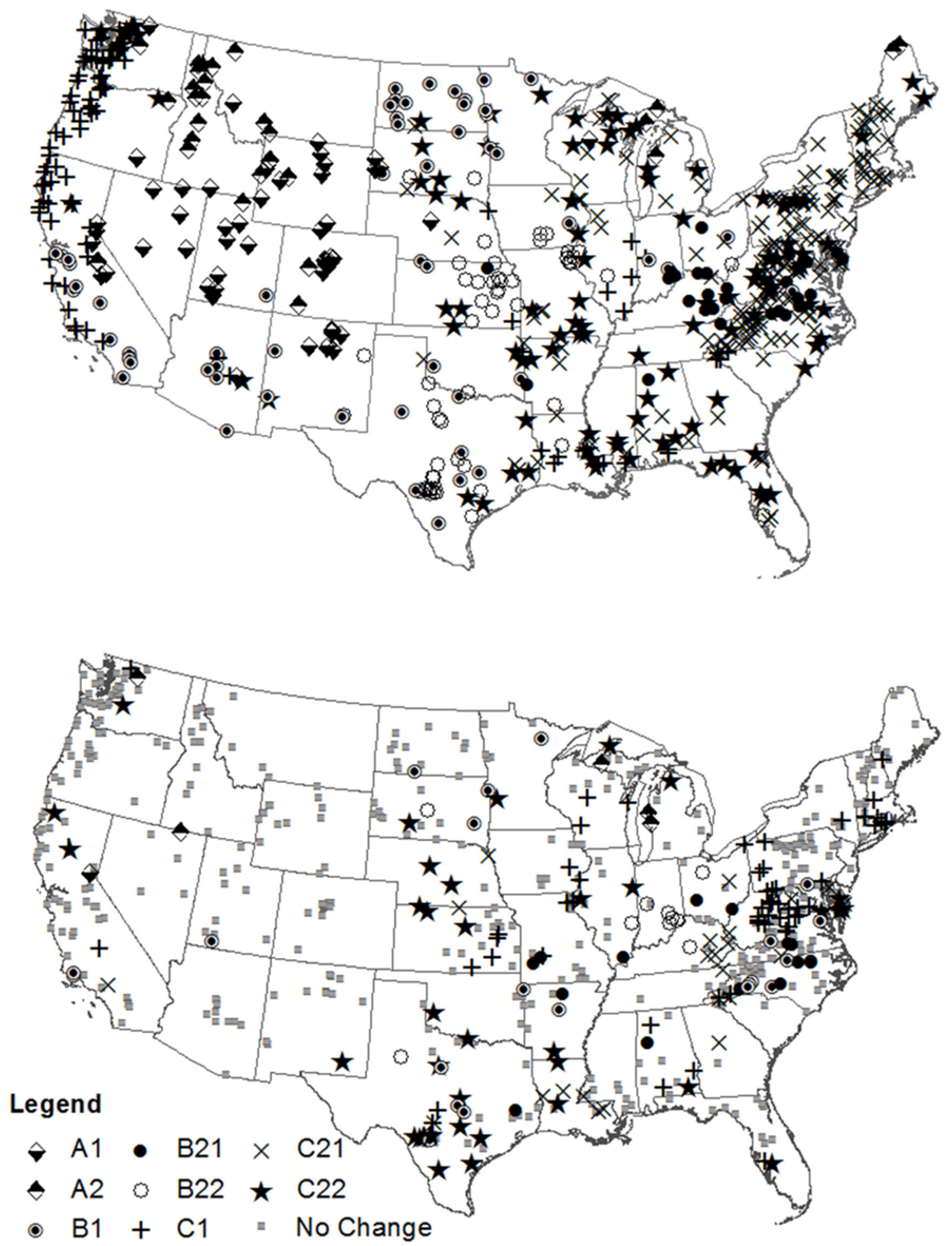

Figure 6. (a) Predicted flow regime classes based on 2000s climate. (b) Predicted flow regime class based on 2090-2999 projected climate change. 


\section{Appendix A: Streamflow Variables Used to Classify Flow Regimes}

Sulochan Dhungel, David G. Tarboton, Jiming Jin, Charles P. Hawkins

Potential Effects of Climate Change on Ecologically Relevant Streamflow Regimes

The following variables were selected to characterize ecologically relevant aspects of the streamflow regime. This relatively small set of flow variables was selected to collectively span the major dimensions of stream flow variation that ecologists view as important in maintaining stream ecosystem structure and function. We tried to avoid excessive statistical redundancy among variables selected and report (Table A-1) correlations among variables evaluated using the 601 GAGES sites used in this study. Additional details on the definition of these variables and examples on their evaluation are given in Dhungel (2014).

1. Zero Flow Event Frequency (ZFE) is the average number of zero flow events per year. A zero flow event is a contiguous series of days within a year when daily flow is zero.

2. Extended Low Flow Index (ELFI) is a combination of Base Flow Index and Zero Days Fraction. Base Flow Index (BFI) is the ratio of lowest daily flow to annual average flow. Zero Days Fraction (ZDF) is fraction of days in a year with zero flow. BFI is zero for streams that go dry, while ZDF is zero for streams that do not go dry. Thus one of these is always zero, and in terms of quantifying the amount of time a stream is dry or how close to becoming dry a stream becomes BFI and ZDF complement each other. ELFI is defined as ELFI $=$ BFI-ZDF to, on a scale from -1 to 1 , quantify both these effects and avoid statistical problems due to a large group of values being at 0 which occurs for BFI and ZDF when they are used separately. 
3. Low Flow Event Frequency (LFE) is the average number of low flow events per year. A low flow event is a contiguous series of days within a year when daily flow falls below the $5^{\text {th }}$ percentile of the entire series.

4. Average 7 day Minimum Flow (Q7min) is the average across years of the minimum of the seven day average flows within a year.

5. Average 7 day Maximum Flow (Q7max) is the average across years of the maximum of the seven day average flows within a year.

6. Bankfull flow (Q167) is the daily flow value that has a probability of exceedance of 1/1.67 from a log-normal probability distribution fit to the annual maximum daily flow series. This is sometimes used in geomorphology as an estimate of bank full flow (Dunne and Leopold, 1978; Poff and Ward, 1989).

7. Flood Duration (FLDDUR) quantifies the duration of flooding as the average number of days per year when the daily flow equals or exceeds Q167.

8. Time of Peak (Tp) is the time of peak flow calculated from the daily average across all the years.

9. High Flow Event Frequency (HFE) is the average number of high flow events per year. A high flow event is a contiguous series of days within a year when daily flow is above the $95^{\text {th }}$ percentile of the entire series.

10. Mean Daily Discharge (QMEAN) is the mean daily discharge.

11. Coefficient of Variation of Daily Flows (DAYCV) is the ratio of the standard deviation of daily flows to the average of daily flows.

12, 13, 14. Colwell's Indices of Predictability (P), Constancy (C) and Contingency (M) are measures of uncertainty based on information theory presented by Colwell (1974). These 
were computed by grouping daily streamflow values into 7 states $(<0.5$ QMEAN, 0.5 QMEAN to 1.0 QMEAN, 1.0 QMEAN to 1.5 QMEAN, 1.5 QMEAN to 2.0 QMEAN, 2.0 QMEAN to 2.5 QMEAN, 2.5 QMEAN to 3.0 QMEAN, >3 QMEAN), following Gordon et al.(2004), and using Shannon's entropy measures to quantify the uncertainty of flow across these states and months. Precise details on our implementation of these calculations are given by Chinnayakanahalli (2010) and Dhungel (2014).

15. Flow reversals $(\mathrm{R})$ is the number of changes of trend from the previous day (increasing to decreasing or vice-versa) each year averaged for all the years of record.

16. T50 is the mean across all years of record of the time of the water year by which $50 \%$ of the total flow has occurred measured in days from October 1. 
Table A-1: Correlation Matrix

\section{$\begin{array}{llllllllllllllll}\text { ELFI } & \text { DAYCV } & \text { QMEAN } & \text { Q167 } & \text { FLDDUR } & \text { P } & \text { C } & \text { M } & \text { T50 } & \text { Tp } & \text { Qmin7 } & \text { Qmax7 } & \text { R } & \text { LFE } & \text { HFE } & \text { ZFE }\end{array}$}

\begin{tabular}{|c|c|c|c|c|c|c|c|c|c|c|c|c|c|c|c|c|}
\hline ELFI & 1 & & & & & & & & & & & & & & & \\
\hline DAYCV & -0.73 & 1 & & & & & & & & & & & & & & \\
\hline QMEAN & 0.29 & -0.41 & 1 & & & & & & & & & & & & & \\
\hline Q167 & 0.04 & -0.05 & 0.91 & 1 & & & & & & & & & & & & \\
\hline FLDDUR & 0.10 & -0.06 & -0.11 & -0.28 & 1 & & & & & & & & & & & \\
\hline $\mathbf{P}$ & -0.40 & 0.50 & -0.28 & -0.16 & 0.42 & 1 & & & & & & & & & & \\
\hline C & -0.44 & 0.69 & -0.40 & -0.16 & 0.25 & 0.82 & 1 & & & & & & & & & \\
\hline $\mathbf{M}$ & 0.30 & -0.54 & 0.21 & -0.05 & 0.34 & 0.06 & -0.43 & 1 & & & & & & & & \\
\hline T50 & 0.06 & 0.04 & -0.18 & -0.27 & 0.47 & 0.32 & 0.28 & 0.07 & 1 & & & & & & & \\
\hline Tp & 0.02 & 0.05 & -0.15 & -0.19 & 0.20 & 0.12 & 0.15 & -0.04 & 0.61 & 1 & & & & & & \\
\hline Qmin7 & 0.77 & -0.70 & 0.78 & 0.55 & 0.00 & -0.47 & -0.58 & 0.36 & -0.04 & -0.05 & 1 & & & & & \\
\hline Qmax7 & 0.08 & -0.13 & 0.95 & 0.97 & -0.12 & -0.12 & -0.18 & 0.06 & -0.17 & -0.15 & 0.61 & 1 & & & & \\
\hline $\mathbf{R}$ & 0.42 & -0.49 & 0.35 & 0.25 & -0.47 & -0.55 & -0.53 & 0.09 & -0.22 & -0.08 & 0.49 & 0.20 & 1 & & & \\
\hline LFE & 0.02 & -0.02 & 0.17 & 0.32 & -0.77 & -0.42 & -0.23 & -0.31 & -0.49 & -0.27 & 0.07 & 0.15 & 0.64 & 1 & & \\
\hline HFE & 0.67 & -0.62 & 0.39 & 0.20 & -0.16 & -0.45 & -0.54 & 0.37 & -0.09 & -0.03 & 0.64 & 0.22 & 0.61 & 0.24 & 1 & \\
\hline ZFE & -0.70 & 0.71 & -0.44 & -0.19 & 0.03 & 0.47 & 0.64 & -0.52 & 0.09 & 0.05 & -0.74 & -0.25 & -0.43 & -0.03 & -0.78 & 1 \\
\hline
\end{tabular}




\section{REFERENCES}

Chinnayakanahalli K 2010, Characterizing ecologically relevant variations in streamflow regimes, Ph.D. thesis, 221 pp., Utah State University, Logan, http://digitalcommons.usu.edu/cgi/viewcontent.cgi?article $=1557 \&$ context $=$ etd

Colwell RK. 1974. Predictability, constancy, and contingency of periodic phenomena. Ecology 55 : 1148-1153. DOI: 10.2307/1940366.

Dhungel S 2014, Prediction of climate change effects on streamflow regime important to stream ecology, 124 pp., Utah State University, Logan, http://digitalcommons.usu.edu/cgi/viewcontent.cgi?article $=4101 \&$ context $=$ etd

Dunne T, Leopold LB. 1978. Water in environmental planning. W. H. Freeman and Co: San Francisco

Gordon ND, McMahon TA, Finlayson BL, Gippel CJ, Nathan RJ. 2004. Stream hydrology - an introduction for ecologists. John Wiley \& Sons: West Sussex, England

Poff NL, Ward JV. 1989. Implications of streamflow variability and predictability for lotic community structure: A regional analysis of streamflow patterns. Canadian Journal of Fisheries and Aquatic Sciences 46 : 1805-1818. DOI: 10.1139/f89-228. 


\section{Appendix B: Watershed Attributes Used in the Predictive Modeling}

Sulochan Dhungel, David G. Tarboton, Jiming Jin, Charles P. Hawkins

Potential Effects of Climate Change on Ecologically Relevant Streamflow Regimes

The following watershed attributes were used as candidate predictors in the random forest modeling. The bold underlined variables are used in the final random forest model.

1. TMIN_WS: Watershed average of the coldest month's PRISM mean monthly air temperature.

2. TMAX_WS: Watershed average of the warmest month's PRISM mean monthly air temperature

3. TMEAN_WS: Watershed average of the annual mean of the PRISM mean monthly air temperature.

4. DIFF_T: TMAX_WS - TMIN_WS

5. DELTAT: Watershed average of the seasonal amplitude of mean monthly temperature. The amplitude of the annual sin/cos cycle fit to the mean across years of PRISM monthly temperature.

6. SD_TMIN_WS: Standard Deviation across each watershed of the coldest month's PRISM mean monthly air temperature.

7. SD_TMAX_WS: Standard Deviation across each watershed of the warmest month's PRISM mean monthly air temperature.

8. MINP_WS: Watershed average of the driest month's PRISM mean monthly precipitation. 
9. MAXP_WS: Watershed average of the wettest month's PRISM mean monthly precipitation.

10. MEANP_WS: Watershed average of the annual mean of the PRISM mean monthly precipitation.

\section{DIFF P : MAXP_WS - MINP_WS}

12. DELTAP: Watershed average of seasonal amplitude of precipitation (Woods, 2003). The amplitude of the annual $\sin / \cos$ cycle fit to the mean across years of PRISM monthly precipitation.

13. PPT50AVG: The point of time in the year (in months counting from the beginning of January) at which cumulative annual precipitation passes $50 \%$ of the total annual precipitation. This is evaluated for each year from PRISM monthly precipitation as a fractional month quantity then averaged across years of record.

$14-25$ PRECIP <Month> SC : Watershed average mean monthly precipitation scaled by dividing by mean annual precipitation. ( $<$ Month $>=$ Jan, Feb, Mar, Apr, May, Jun, Jul, Aug, Sep, Oct, Nov, Dec)

26. PROPSNX : Watershed average of mean proportion of precipitation that occurs in months when $\max$ temp $<0 \mathrm{C}$. The months with PRISM max temperature $<0 \mathrm{C}$ are determined each year and the proportion of precipitation determined for these months each year and averaged across years of record.

27. PRECSNX: Watershed average of the annual average of yearly precipitation that occurs in months when max temp $<0 \mathrm{C}$. The months with PRISM max temperature $<0 \mathrm{C}$ are determined each year and the amount of precipitation summed for these months each year and averaged across years of record. 
28. PROPSNM: Watershed average of mean proportion of precipitation that occurs in months when mean temp $<0 \mathrm{C}$. The months with PRISM mean temperature $<0 \mathrm{C}$ are determined each year and the proportion of precipitation determined for these months each year and averaged across years of record.

29. PREC SNM: Watershed average of the annual average of yearly precipitation that occurs in months when mean temp $<0^{0} \mathrm{C}$. The months with PRISM mean temperature $<0^{0} \mathrm{C}$ are determined each year and the amount of precipitation summed for these months each year and averaged across years of record.

30. RH_WS: Watershed average of the annual mean of the PRISM mean monthly relative humidity.

31. PETBAR: Watershed average of the mean annual potential evapotranspiration.

32. RDRYNESS: Climate Dryness Index (Woods, 2003), the ratio of PETBAR to MEANP_WS.

33. DELTAE: Seasonal amplitude of potential evapotranspiration (Woods, 2003).

34. SEASONALITY: Climate seasonality index (Woods, 2003).

35. AREA: Watershed Area in sq. km.

36. ELEV MEAN: Mean watershed elevation.

37. ELEV_MIN: Minimum elevation in the watershed.

38. ELEV_MAX: Maximum elevation in the watershed.

39. ELEV_STD: Standard Deviation in the watershed.

40. SHAPE1: Ratio of the watershed area to the square of the longest distance to the outlet on the flow path

41. MEANSLP: Watershed average topographic Slope. 
42. STDSLP: Standard Deviation of topographic slope.

43. DDEN: Drainage density in meters of stream per square meter of watershed determined from the stream network as created from drop analysis (Tarboton et al., 1988).

44. HYPSOMETRIC CONVEXITY: Dimensionless elevation-relief ratio calculated as (ELEV_MED-ELEV_MIN)/(ELEV_MAX-ELEV_MIN) where ELEV_MED is the median elevation within a watershed.

45. AWCH_AVE: Watershed average of available water capacity of soils

46. BDH_AVE: Watershed average of soil bulk density.

47. KFCT_AVE: Watershed average of soil erodibility factor.

48. OMH_AVE: Watershed mean high value of soil organic matter content.

49. PRMH AVE: Watershed mean high values of soil permeability.

50. WTDH_AVE:Watershed average high values of seasonally high water table(from STATSGO).

51.RDH_AVE: Watershed mean high values to depth to bedrock.

\section{REFERENCES}

Tarboton DG, Bras RL, Rodriguez-Iturbe I. 1988. The fractal nature of river networks. Water Resources Research 24 : 1317-1322. DOI: 10.1029/WR024i008p01317.

Woods R. 2003. The relative roles of climate, soil, vegetation and topography in determining seasonal and long-term catchment dynamics. Advances in Water Resources 26 : 295-309. DOI: $10.1016 / \mathrm{S} 0309-1708(02) 00164-1$. 